\title{
Creating conditions for participation - conflicts and resources in systems design
}

\author{
Susanne B $\phi d k e r$ \\ Dept. of Computer Science \\ Aarhus University \\ Ny Munkegade \\ DK-8000 Aarhus C, DENMARK \\ Tel: +45-89423256 \\ E-mail:bodker@daimi.aau.dk
}

To be presented at PDC '94

\begin{abstract}
User participation in design is a well recognized way of gaining more knowledge about work, and of improving the quality of the computer application to be designed. Yet many experiences with user participation were gained under circumstances quite different from those of corporations in the 1990 's - in the Scandinavian collective resource projects. This paper will argue that a lot can still be learned from these projects, in particular when it comes to the creation of conditions for participation.

The paper will present a recent project, the AT project, in order to discuss the concerns and conditions of participatory design projects today. This discussion seeks inspiration also in philosophical concerns regarding human development. The main message is that we shouldn't throw out the baby with the bath water, though certainly many aspects need to be rethought. The paper goes on to suggest that new alliances between groups in organizations, with due concern for their diversity of resources, and with constructive use of the conflicts inherent in the organization despite their fundamentally conflicting interests, may be a way forward in empowering organizations, making room for groups and individuals within them to act. The paper discusses experiences with ways of setting up design activities in such an environment.
\end{abstract}

KEYWORDS: empowering, conditions and methods for participatory systems design. 


\section{INTRODUCTION}

User participation, as a way of gaining knowledge about work and thus of improving the quality of the computer application, shows many problems, including:

- The collective experiences of participation are often only for those directly involved in the project, and only while the process is running. A forum for co-operation between the directly involved participants and their different peer groups or organizations, and continuity/history between projects are often missing.

- The issues of power and resources are in many cases never considered: users are selected to participate without support from peers. They cannot set up their own investigations, and often they cannot even call a meeting with fellow workers during working hours. And in the end, management has the power to decide what to do, in which cases the enrolled users are trapped: they are committed to the system and their words are taken to represent "the users", yet they have no support from these.

- Users often spend time in systems development projects without compensation from their normal work load, and

- there often are no resources for users to educate themselves as part of a project.

Thus, while user participation, in a narrow sense may improve the quality of systems design, the above problems remain to be explored. I will demonstrate how the Scandinavian collective resource tradition, though it has been denounced by some [1], has a lot to offer this discussion (see also [15]). No doubt, however, these projects were carried out under conditions that are far away from the reality of most participatory design today. I will present a case in order to discuss such more recent concerns and conditions. This case, the AT-project, was a cooperation project between Aarhus University and the local branch of the Danish National Labor Inspection Service (NLIS). A purpose of the project was to design a number of computer applications for the branch and to develop a long-term strategy for decentralized development and maintenance.

The concerns of the AT-project is further discussed by being "mirrored" against other ways of understanding participation and development, living in Scandinavia today: the Danish philosopher Grundtvig's thoughts on human growth, and the Finnish developmental work research approach.

\section{THE EARLY PROJECTS - LEARNING TO RE-COGNIZE CONFLICTING INTERESTS, GOALS, AND DIVERSITY OF RESOURCES.}

In Scandinavia, research projects on user participation in systems development date back to the 1970's. The so-called collective resource approach developed strategies and techniques for workers to influence the design and use of computer applications at the workplace: The Norwegian Iron and Metal Workers Union (NJMF) project took a first move from traditional research to working with people, directly changing the role of the union clubs in the project [10].

Not only did the Scandinavian projects develop an action research approach, they also rejected, e.g., the traditional use of systems descriptions, pointing out that systems description with users is a process, stressing the collective build-up of resources and knowledge [20]. The key issue was building on people's own experiences, providing for them resources to be able to act in their current situation.

The harmony view of organizations, according to which conflicts in an organization are regarded as pseudo-conflicts dissolved by good analysis and increased communication, was rejected in favour 
of a view of organizations recognizing fundamental "un-dissolvable" conflicts in organizations [11, $8]$.

Education of union representatives is one way that the project helped build up resources for local actions. The DUE project offered a one week course to up to 500 union members a year for approximately 13 years. A major part of the course consisted of group work to develop and discuss immediate local union actions. Furthermore the courses dealt with long term actions, potentials and problems of computer technology, systems design focusing on user participation, the role of the union movement, of technology agreements, and cases from various workplaces.

In the later Utopia project $[7,12]$, these experiences were the starting point, and certainly provided a perspective underlying the whole project. Yet, when looking back on Utopia, the major practical as well as theoretical achievements in the project were the experience-based design methods, developed through the focus on hands-on experiences, emphasizing the need for technical as well as organizational alternatives [7]. The Utopia project, furthermore, demonstrated the potentials as well as problems of working with one group of workers (printers and typographers) in a world (of newspapers) where also other groups, e.g. journalists, as well as management have significant interests.

We may summarize the important focus points from the early "Scandinavian" projects in the following (see fig. 1): Based on a fundamental understanding of organizations as inherently full of conflicts they developed a way of thinking about systems design that focused on technological and work-organizational alternatives, where the education of users to participate in design was important as were design methods emphasizing the work experiences of the users. Exactly these points are worth holding on to in the present (Scandinavian) society, which becomes increasingly more complex and fragmented [14], and where the role of labour unions becomes increasingly less significant. Where, in the 1970's and early 1980's, the Labour Unions were a natural allied in attempts to democratize participation in systems design, this is no longer the case, which does not, in my view, justify a total rejection of what the collective resource approach stood for.

\begin{tabular}{lll} 
& Early projects & Utopia \\
Purpose & Helping people influence technology in their everyday lives \\
& Resources for local action Possible technical and org. alternatives \\
Partners & Local unions & Central unions \\
World view & Organization inherently full of conflicts \\
Work methods Trad. design \& research Participatory, experience-based. \\
\multicolumn{2}{c}{ Education }
\end{tabular}

Fig. 1 Summary of earlier projects

\section{A THIRD GENERATION PROJECT}

The cooperation project with the local branch of the Danish National Labor Inspection Service (NLIS), called the AT project [9], belonged to the generation of empirical projects following Utopia. The project emphasized resource build-up for the participants, in a setting different from the earlier projects: first of all because management as well as employees took part, secondly because we were dealing with an organization that was to live with the technology after the project ended. Thus, the topics of resources, experiences, education, etc. needed to be re-thought in this new setting, and new experiences fed back into our thinking about participation in design. In our reinterpretation, resource build-up means to improve the ability of the organization to maintain experiences and be able to act better in the future with respect to technological change processes. What one does in a project is not only for the project, it should put the organization in a position 
where the experiences can be used, by the organization on its own, further on in time, in particular with respect to the further development of the technology (tailorability, etc.).

\section{Exploring the setting of the AT project}

The NLIS is a state institution that inspects and advises companies about health and safety matters. Participating in the project from the Arhus branch of the NLIS were 40-50 people from a variety of occupations including secretaries, administrative workers, machinists, engineers, lawyers, and therapists.

When the AT-project started, most work at the NLIS was done through paper forms, that were circulated and filed in large archives. The Labour Inspection had access to VIRK [6] a centralized computer system applied to record the interaction of NLIS with companies. Visits to work sites as well as correspondence with companies were recorded, and extracted. VIRK is a menu-based system running on terminals. Nowadays, VIRK can be accessed also from PCs. NLIS uses PCs, Word Perfect, and Windows as a result of the AT project.

In the early days of the project, the inspectors worked rather individually, each focusing on his specific set of companies. The work was supported by secretaries who typed and filed. During the project, work underwent change to consist of groups organized according to which companies to inspect. What was formerly centralized administrative work was distributed across groups. Secretaries who had worked in a pool were assigned to specific groups. These working groups were granted a certain responsible autonomy regarding execution. Control of work became more and more centralized, within the branch office as well as in the organization in general, and this led to more and more accounting for work in quantitative terms [18]. At the end of the project, work was yet again reorganized, changing the groups, and with the PC technology, secretaries no longer write for the inspectors. The inspectors do all of their writing, and most of their information retrieval themselves. Today all inspectors use portable PCs with docking stations.

Management of the Aarhus branch consisted, initially, of a manager and two deputy managers, one responsible for inspection and one for administration. At the end of 1991 this changed: a new toplevel manager arrived and the deputy manager level disappeared. This led to further organizational changes, as well as a totally different management style.

NLIS follows the lines of the bilateral agreement between Danish employer and employee organizations regarding cooperation and technology. The agreement institutionalizes a co-operation committee, consisting of management representatives and employee/union representatives, who must agree on principal issues and guidelines regarding, e.g., vocational training and technology.

With respect to the AT project, the NLIS co-operation committee has been consulted, in particular regarding the selection of participants for various activities, but has otherwise remained rather passive. We have worked with local management as well as employees, mainly those who were most interested in technology or in the change process. Some of the working groups at NLIS had the opportunity to choose to work with us. These working groups were in many ways rather autonomous, and technology issues, as well as their own organization of work were a natural part of their collective endeavour.

Resources, such as time, needed to be negotiated with management as well as with the co-operation committee. Actually our rather informal way of setting up the project organization has been a problem in this respect. Sometimes the working groups have themselves taken on the duty of negotiation resources for their participation with management. Other times, we have done so. On some occasions we have been asked by the employees to act as their advocates towards management and the central office of NLIS. In other cases, management has asked us to act as their consultants. We have found it important to enter all these roles, as long as what happened was known and transparent to everybody. We believe that this is possible only to the extent that we 
were trusted by all parties, and because we have quite carefully analyzed the potential conflicts in the situations. Yet, when NLIS got new management we experienced a backlash where a more clear-cut definition of roles and interests was to be preferred, because obviously a new manager coming from outside did not share the trust and experiences with an "outside" project already in place.

Thinking about the participants differ in this project from the earlier ones, which were centred around negotiations between management on the one hand and the workers' collective (i.e. the local unions) on the other. The present situation does not lend itself to such an easily identified conflict. Thus, where the earlier projects focused strongly on building up resources for local unions to work with, and act around questions regarding technology primarily to prepare themselves for negotiations with management [11], the resource build-up was framed differently in the AT project: We have found it important to look at the individual level as well as various collective ones, including e.g. the group of secretaries, the work branch groups, and the organization as such.

In the earlier one-party projects the problem to be fought was that of rude exploitation, personified by management. The situation at NLIS was, however much more vague:

- the quality debate had strongly influenced management as well as workers, at the same time though as management still had a strong interest in rationalization,

- inspection work is not readily taylorized, and part of the debate in NLIS circles moved in the direction of more holistic work tasks (where e.g. inspectors write up letters themselves, secretaries do case work)

- we were not really dealing with a workers' collective [17], such as what was assumed when working with local unions in the earlier projects. Rather, the problems and possibilities are strongly individualized, and the "enemy" internalized in the individual workers. This enemy can to a large extent be characterized as "those things spoiling quality".

\section{Contradictions and conflicts as conditions for participation in design}

Within the organization there are numerous conflicts which constitute part of the constraints and possibilities for design. Furthermore, as pointed out by e.g. [2], the design process as such create new conflicts, because it opens new possibilities and "threatens" existing structures, procedures, etc.

In [6], I conclude that " It is no coincidence that the secretaries and inspectors are the ones who ask for computer support that can be characterized as media or tools, whereas what management has asked for in VIRK is a system. Clashes between these views are seen throughout the use of VIRK." This example furthermore addresses the more overall issue of the purpose of labour inspection: is it to make as many claims to companies as possible, or to make more long-term cooperation with the companies to improve working conditions. This in turn addresses the conflict between efficiency of inspection, very much a concern of management, and quality of inspection, a concern for most inspectors.

In the case study, we have been concerned also with conflicts between the organization of work on the one hand and the quality of the product on the other: before the advent of PCs the secretaries did most of the typing and thus of the finalization of letters. With the PCs this job was left to the inspectors, partly with the argument of double work. And certainly spell checking, and standard formats, have made life without secretaries possible. What may be of most concern is that inspectors are catalogization and filing material as well, where earlier this was left in the hands of a handful of secretaries. Each inspector does his catalogization less frequently, and less cooperatively (and, of course, the secretaries would claim, less carefully). What is at risk here, is really the longterm possibilities of retrieving the material, once it is filed. 
Regarding new conflicts introduced through the research and design project, the most important one has to do with the attention given to the core group of participants who were selected to work with us: they all got PCs and attention from researchers and management, and they got various chances to go away for workshops, etc. For many NLIS workers this group was from the outset very "strong", and this perception was enforced in the process, making it even more necessary to work with other groups as well, and to be very open with respect to what happened in the core group.

Furthermore, in particular the possibility for inspectors to write up their own letters introduced conflicts with the group of secretaries. Because of a profound worry from most of the secretaries as individuals of loosing their job, this conflict has mainly surfaced as individual frustration, not as collective action.

The last kind of conflicts we have ourselves been part of: as researchers we have primarily been working with those groups and individuals who have chosen to work with us. Also we have often ended up doing e.g. prototyping with those who were interested, rather than with a broad spectrum of workers. Partly this is because of our own blindness, partly it is because we have found it hard to turn down those who volunteer. Underlying this we have chosen to work with people as equal participants. However they also have a relationship with one another outside our project, and sometimes these two sets of "roles" have been somewhat conflicting.

\section{HOW DID WE DO DIFFERENTLY? - WORKING WITH PARTICIPATORY DESIGN IN THE AT-PROJECT}

The work methods and history of the AT project is described in $[6,9,19]$, and elsewhere. Here I shall look at a couple of examples, to illustrate the changes in conditions and concerns of the AT project, as compared to the earlier Scandinavian ones.

\section{Working with both managers and ordinary users}

After some initial field work, we decided to hold a seminar with people from NLIS. In preparation for this, we held a future workshop. Most of the employees (40) participated in this half-day workshop, held during their monthly staff meeting. In this future workshop, management agreed not to participate. This decision was not based on mistrust between management and the designers. Rather, our experience had been that future workshop participants are reluctant to criticize when management participates, and hence ideas for improvement sometimes get lost. Management found this to be a valid argument for not participating.

The main seminar was held over three days. Ten people from Århus-NLIS and 6 AU researchers attended. The former were chosen to represent inspectors, secretaries, as well as managers. The seminar included an extended organizational game and work with mock-ups and prototypes of future technologies. Compared to the future workshop, the idea was for the seminar to be more structured and focused (though on a number of topics) and we had a number of discussions about the role of management in the seminar. We decided that the topics were so clear that it was possible to let the participants confront their opinions with one another. And the managers were not to be in a different position than the rest, i.e. the managers were not given special time, and they had to take part in the organizational game in the same way as the rest. Throughout these activities we were highly dependent on management's accept of the roles that we asked from them, i.e. on their judgement that our suggestions made sense, and their ability to step aside and be part of democratic situations.

\section{Being visionary with standard technology}

NLIS headquarters decided to buy PCs for the Århus branch as a first step toward new technology for the entire organization. As a consequence we embarked on a consultant-style relationship. This moved the project direction from our research goals, to the practical necessities of helping NLIS in 
their current situation. The relation between the NLIS branch office and the computing department in Copenhagen was such that they could not expect much real help. It was important for us as researchers to help establish a sound technological platform, that would live on despite the resistance from outside. The actual negotiations with the directorate, etc. were all along handled by the NLIS.

At the same time the organization reorganized to work in groups of inspectors and secretaries. The researchers saw this as an opportunity to start a more systematic effort of introducing the PCs in the organization, instead of just spreading what was available in the organization at random. After negotiations, one group was selected to become users of the first PCs. The idea was that the experiences from this core group, as well as technical and organizational solutions encountered in the group should later expand to the rest of the organisation, and we decided to focus our project on two of groups, one of which was to receive new PCs; the other focusing on developing their use of existing mainframe-based technology.

Our consulting activity during this period included helping customize Windows and WordPerfect, and an education regarding the use of WP. In our work we centred the activities around work in peer groups, thus making the participants aware that they can get help from the "experts" among themselves.

A two-level strategy was developed [4]. At one level, a technical and educational minimal platform was established. It consisted of very few programs for the most needed things such as text processing. The users were taught how to use these programs and slowly they began to work with them. Immediate organizational problems and changes were discussed. Small, consolidated steps of change were all the time implemented to improve the immediate situation. At the same time, at the top level, we kept on shedding light on thorough changes. It did not seem as a very good idea to hold back on the PCs until we were absolutely sure which programs were to be put onto the computers. Thus we aimed for a strategy which would deliberately make use of the fact that we had the PCs at hand.

We were, in this case, not too pleased with the choice of basic technology made for us, the PC world. At the same time, though, there are so many good standard products available today, e.g. for office work, that it seems inappropriate to start a design process from scratch. Furthermore, we believe that doing systems design in an organization which is a total computer novice will soon become a rare exception, which will make it necessary to develop design strategies where the present computer use (experiences as well as software and hardware) constitutes the basis for the further change.

\section{Resources for the whole organization as well as groups within it}

Though our goal was to work with the whole organization, it is most certainly not possible to work with everybody all the time, and, as outlined above, it is not necessarily what one wants. The challenge to keep the remains of the organization oriented about what happened in the project was undertaken in various ways:

- After cooperative prototyping at the seminar, the prototype was place for a couple of days at the NLIS, in order to encourage interest and discussion also among the people who were not directly participating in the seminar.

- Throughout the process we published a newsletter to everybody in the branch office, where we, and some of the participants presented experiences in order to have a continous dialogue between the direct participants and the remains of the organization.

- The project was discussed at the regular staff meetings. Time, however is the ultimate factor with respect to how much involvement of the whole organization is enough. The cooperation committee, 
and the unions were, after some initial interest in the set-up of the project rather passive, though individuals from management as well as labour side were active in the project.

\section{THE SITUATION AT THE END OF THE PROJECT}

How did the project help build up resources for the organization, or groups in the organization, once the designers/researchers have pulled out? This topic is not often dealt with in literature, thus, we cannot easily compare our experiences with those of other projects. Furthermore, it is a difficult topic, because a successful pull-out is hardly visible, except, perhaps in retrospect for the researchers. For the use organization, the more the work methods of the project have become a part of the everyday life, and the less they "miss" the researchers, the better.

At the technical level we have been successful in many ways:

The continued design is primarily carried out by two inspectors who have official tailor roles in the organization, and a temporary programmer, who is in charge of network and such $[5,21]$. Initially, standards developed and spread rather anarchistically. Now the procedure has become more systematic: the programmer and the tailors pick up ideas, and make standards. Every once in a while, these standards are collected and set up on all machines [21].

The NLIS people are very proud of what they call the NLIS approach to WP, using plenty of (hierarchical) button panels on the screen for various specific tasks. This approach was, though this was long forgotten, introduced through the AT project.

Tailors at the NLIS are professionals working in the fields they have chosen and for which they've been trained, at the same time as they are technology "developers," a new, unfamiliar undertaking. The positive side of this is that the development activity remains fully embedded in a professional work life; the down side however is that tailors struggle with the conflicting demands coming from the two worlds.

Everybody is encouraged to bring up new ideas for tailoring, and there are no formalities by which a good idea is turned down. By virtue of their more developed insight into the technology, and the overview that they have from talking to other people about ideas and needs, the tailors bring about most of the ideas. For most standards, it is entirely up to the tailors and the programmer to judge whether they are worth while distributing. Attempts have been made to organizationally structure the tailoring process through a Technology Committee [5].

Management has little concern for tailoring as long as there are no problems. There is little recognition of the fact that this ongoing development, including training and tailoring, costs.

It is probably not realistic for everybody to achieve the same level of competence and participation regarding technology, as I see it. This new group of experts, the tailors, though more directly situated in the organization, runs the same risk of being detached from the everyday life and problems of the users, as are often seen in more traditional systems development. Yet they provide better possibilities of including reflexivity [14] in the use/work processes, because they after all are working in the organization, as labour inspectors alongside the rest. It is an important challenge for participatory design to understand and encourage ways of avoiding a too widespread disembedding of the tailoring activities from the remains of the use organization.

\section{REINTERPRETING CONCERNS FROM THE PROJECT}

In the following, I shall seek inspiration for interpretation and expansion of the concerns of the ATproject from two, at the surface rather different, sources: a 200 years old Danish clergyman, and a Finnish psychologist of our own time. My reason for picking the two is that they, in my view, 
represent two highly viable alternative ways of thinking about human development at a collective as well as an individual level. 


\section{Growing}

The Danish clergyman, educationalist, and philosopher Nikolaj Frederik Severin Grundtvig (17831872) thoroughly reformed the Scandinavian educational systems, and his ways of thinking still lives in many areas of Danish society. Grundtvig believed that human beings were put in this world to grow. A grim and pitiful life on earth is not, he believed, a precondition for a next life in heaven. On the contrary, we have every reason to make life on earth better for everybody collectively [16]. Grundtvig suggested the use of common-sense language in the person's mother tongue in reciprocal teaching, founding learning in the every-day life experience of the learners. He organized high-schools for young peasants to educate themselves in historical and cultural matters. As opposed to the normal schools the idea was for them to come of their own choice (as adults), meet the "spoken word" (i.e. experience and discuss with culturally important persons and events) instead of rather detached reading about culture, and have their education rooted in their own experiences and history. In Grundtvig's thinking such education is a prerequisite for coping with growth, as well as for wanting it for one self. Since systems development is per se a situation of growth, "threatening" our safe everyday being in the world [3], many of Grundtvig's thoughts are rather challenging: a general education in matters around systems development seems to be important to be able to take part, this education must arise out of the users everyday experiences, and be in dialogue with peers and with the educators. These, in turn, must be people who actively embody the culture, in this case computer systems development and use, in a wide sense.

Furthermore, the thoughts of Grundtvig, being as firmly consolidated in Danish culture as they are, may provide a perspective to help understand the role of management of NLIS in the AT-project. Grundtvig's anti-elitist perspective on the access to knowledge is, in my mind, quite fundamental in understanding why Danish society and worklife is as relatively open as it is.

\section{Developmental work research}

Inspired by the socio-cultural tradition of activity theory (Vygotsky, Leontjev), the Finnish psychologist and educationalist Yrjö Engeström and others have developed their developmental work research approach. This approach is an action-oriented approach to studying learning and change in work.

Engeström [13] is looking at change processes in organizational settings and sees contradictions of various kinds as the cornerstones of such change. For instance, the artifacts that we work with are under a constant reconstruction, due to conflicts in the way they are applied. These conflicts occur at a number of levels, due to which the reconstruction cycles are different in size. Engeström comes up with a way of utilizing interrelated, yet conflicting activities in the process of change of work. Change is seen as a collective learning process where two principles are fundamental: the application of a methodological cycle, and the notion of the zone of proximal development.

The methodological cycle is moving from an analysis of the activity and the surrounding activities, to the creation of instruments by which the practitioners can transcend their own praxis, thus creating a vision of the change, to an implementation of a final new instrument into the organization. The idea here is, that inasmuch as we try to predict how praxis will change, artifacts are used differently from the original intentions, and new contradictions are always introduced, causing the need for new artifacts to arise.

Engeström uses Vygotsky's notion of a zone of proximal development [13] to understand along which lines such a learning can take place. Vygotsky's idea is that besides from a person's present skills and understanding there is a zone, within which the person is capable of/ motivated to learn. Vygotsky share with Grundtvig the view that there is no learning if it does not result in the development of the human being. Engeström strongly emphasize that we must look at the collective level: In his reformulation, the zone of proximal development is the distance or path between what a group can do at present, and what it comes to understand as possible new ways of acting; new 
ways which transcends some of the problems of the present daily work. Thus, Engeström's ideas and methodology are extending those of Grundtvig in dealing with collective growth.

We also get a handle on these collective levels methodologically. Engeström's framework gives some help to understand these different roles and interests, and to make use of them in design. How to support the resource build-up in such a diverse environment is definitely an interesting question to proceed with.

In systems development, it is not very clear in which direction one is heading, and it is often discussed where new ideas come from. With the above methodological cycle, Engeström offers his suggestion for how groups transcend their own praxis. Expansion, thus, ought to be essential in systems development where nobody knows the answers on beforehand.

One aspect where the collective resource tradition, however, stands stronger than work development research is, in my view, when it comes to direct participation in the analysis and design of work. I see no reason, however, why future workshops, etc. could not be included in the repertoire of methods applied by work development research.

\section{ADDING UP THE CONCERNS}

Of the concerns of the original Collective Resource projects, an awareness towards resources and conflicts still stands. Resources is a matter of what kind of competencies get build up within (groups in) organizations to be able to take action regarding development and use of computer technology, not only a matter of money. And looking at conflicts means not just conflicts between employers and employees in the traditional sense, the concept is usefully extended as suggested by Engeström. Grundtvig's thoughts about collective growth are useful in dealing with an organizational unit such as the Aarhus branch office of NLIS. There is still some work to be done to involve, in a satisfactory way, several groups within the organization at the same time. The concept of quality of the design process is strongly tied to the resource build-up for these various groups.

Access to tailorable off-the-shelf software becomes more and more wide-spread. Experiences from NLIS [5] enforces the impression that a two-level strategy is necessary, or at least that situated, local problem solving is not sufficient. Within the project we quite successfully worked with both levels, whereas it is questionable whether the top level concerns will be dealt with also in the future. This may be a problem for a more long-term expansive development of technology use, and for technical problems of consistency, complexity, etc.

Our suggestion to start the work with technology in a small group, what Engeström [13] calls microcosmos, was clearly a success. Partly because it allowed a real working group to apply technology, thus adding an element of realism to the experiment, and partly because it allowed the organization, and the tailors in particular, to gain experiences on a small scale. As pointed out above, it is necessary to launch a process to involve the rest of the organization alongside. In the AT-project, this process had the form of newsletters and of "public" demonstrations of prototypes, and is definitely a point where we could have done more.

A further fundamental question, in situations like the NLIS, where much design is a matter of local adaptation of standard technology, is how "globally" we may support local participatory design, i.e. local resource build up? First of all flexible, tailorable standard technology is a necessity. This does not do the trick alone, though. It is important to rethink the design process to include structures through which ordinary people at their work place more democratically can promote their own interests. The decreased interest and apparent importance (e.g. from the point-of-view of top management) of each systems development process provide an interesting opportunity for the people who are actually affected by the changes to take part in the design process. How this potential is crystallized into actual influence is to a large extent dependent on knowing how to work with 
these issues. Ironically this research interest was specifically the focus of the early Collective Resource Approach projects.

$\begin{array}{ll}\text { Purpose } & \text { AT } \\ & \text { Helping people influence technology in their everyday lives } \\ \text { Partners } & \text { Empowering the organization for local action } \\ \text { World view } \quad \text { Managers and workers of the organization } \\ \text { Organization inherently full of conflicts, which may be used constructively } \\ \text { in design. Fundamental conflicts cannot be dissolved } \\ \begin{array}{c}\text { methods Participatory, experience-based. Applying and tailoring standard } \\ \text { technology. }\end{array}\end{array}$

2-level strategy. Microcosmos.

Fig. 2. Summary of the AT project.

\section{Acknowledgements:}

Thanks to Ellen Christiansen, Pelle Ehn, Morten Kyng, Randi Markussen, Randy Trigg, and in particular to Preben Mogensen for cooperation, as well as comments on this paper, and to all of the people at NLIS, who I have enjoyed spending time with for the last years. This work has been supported by the Aarhus University Research Fund.

\section{References:}

1. Bansler, J. \& Kraft, P. (1992) The collective resource approach: the Scandinavian experience, in Muller, M., Kuhn, S. \& Meskill, J. (eds.) PDC 92, pp. 127-136.

2. Borum, F. \& Enderud, H. (1981). Konflikter i organisationer - belyst ved studiet af edbsystemarbejde [Conflicts in organizations - seen through the study of computer systems development] Nyt Nordisk Forlag Arnold Busk, Copenhagen.

3. Brun, J. Vaksttanken hos Grundtvig [Grundtvig's notion of growth]

4. Bødker, S. \& Mogensen, P. (in preparation). A two-level strategy for evolutionary design. Dept. of Computer Science, Aarhus University.

5. Bødker, S. \& Trigg, R. (in preparation). Living with standard applications, Dept. of Computer Science, Aarhus University.

6. Bødker, S. (1993). Historical analysis and conflicting perspectives - contextualizing HCI. In Bass, L., Gornostaev, J., Unger, C. Human-Computer inter-action. 3rd International Conference, EWHCI '93, Springer Lecture Notes in Computer Science vol 753, pp.1-10.

7. Bødker, S., Ehn, P., Kammersgaard, J., Kyng, M., \& Sundblad, Y. (1987). A Utopian experience. In G. Bjerknes, P. Ehn, \& M. Kyng. (eds.), Computers and democracy: A Scandi-avian challenge. (pp. 251-278) Aldershot, UK: Avebury.

8. Bødker, S., Ehn, P., Knudsen, J. L., Kyng, M., \& Madsen, K. H. (1988). Computer Support for Cooperative Design. In Proceedings of Conference on CSCW, Portland, Oregon, September 1988 (pp. 377-394), New York: ACM. Also available as DAIMI PB 262, Aarhus University, Denmark, 1988, pp. 377-394.

9. Bødker, S., Christiansen, E., Ehn, P., Markussen, R., Mogensen, P., \& Trigg, R. (1993). The AT-Project: Practical research in cooperative design (DAIMI No. PB-454). Computer Science Department, Aarhus Uni-versity, Denmark.

10. Ehn, P. \& Kyng, M. (1987). The Collective Resource Approach to Systems Design, in Bjerknes, G. et al. (eds.): Computers and Democracy - a Scandinavian Challenge, (pp. 1758) Avebury

11. Ehn, P. and Sandberg, Å. (1979) 'God utredning ' in Sandberg, Å. (ed.): Utredning och förändring i förvaltningen, Liber förlag, Stockholm. 
12. Ehn, P. (1988). Work-oriented design of computer artifacts. Falköping:

Arbetslivscentrum/Almqvist \& Wiksell International, Hillsdale, NJ: Lawrence Erlbaum Associate.

13. Engeström, Y. (1987). Learning by expanding. Helsinki, Orienta-Konsultit.

14. Giddens, A. (1990) The consequences of modernity, Stanford, CA: Stanford University Press.

15. Kyng, M. (1994) Collective Resources meet puritanism, Scandinavian Journal of Information Systems 6:1, pp. 85-96.

16. Larsen, E. (1974) Grundtvig- og noget om Marx [Grundtvig - and something about Marx] Arken Tryk, Kolding.

17. Lysgaard, S.: Arbeiderkollektivet, [The Workers' Collective] Universitetsforlaget, Oslo 1976

18. Markussen, R. (1993). A historical perspective on work practices and technology. In P. B. Andersen, B. Holmqvist, \& J. F. Jensen (Eds.), The Computer as Medium. Cambridge, UK: Cambridge University Press, pp. 457-476.

19. Mogensen, P. (1994). Cooperative analysis, Ph.D. thesis, Aarhus University.

20. Munk-Madsen, A.(1978) Systembeskrivelse med brugere, DUE-notat no. 9, University of Aarhus [Systems Description with Users]

21. Trigg, R. \& Bødker, S. (in preparation) From implementation to design: Tailoring and the emergence of systematization in CSCW, CSCW '94. 
